\title{
A crise teleológica das Ciências Modernas em Edmund Husserl
}

\section{The teleological crisis of the modern sciences in Edmund Husserl}

\author{
Marcelo Rosa Vieira \\ Mestre em Filosofia \\ (Universidade Federal de \\ Uberlândia); professor \\ substituto do IFILO-UFU \\ marcelroust@hotmail.com
}

Recebido em 30/06/2018 Aceito em 30/10/2018
Resumo

O tema a ser tratado aqui é a questão da história da crise teleológica das ciências modernas no pensamento tardio de Edmund Husserl. Tomaremos como referência, para essa tarefa, a obra tardia do filósofo: "A crise das ciências europeias e a fenomenologia transcendental", na qual ele assume o ponto de vista de que as ciências europeias atravessam uma grave crise de sentido desde a revolução científica no século XVII. Época na qual tais ciências, reduzindo o mundo ao conjunto dos fatos para poder medi-lo, quantificá-lo, determiná-lo, perdem de vista a subjetividade e já não se tornam mais capazes de dar um significado para a existência humana.

Palavras-chave: Fenomenologia. Crise. História. Ciências Modernas. Husserl.

\section{Abstract}

The subject to be dealt with here is the question of the history of the teleological crisis of the modern sciences in the late thinking of Edmund Husserl. We will take as a reference for this task the late work of the philosopher: "The crisis of the European sciences and the transcendental phenomenology", in which he takes the view that the European sciences are going through a serious crisis of meaning since the scientific revolution in the seventeenth century. Time in which such sciences, reducing the world to the set of facts to be able to measure it, quantify it, determine it, lose sight of subjectivity and no longer become capable of giving meaning to human existence.

Keywords: Phenomenology. Crisis. History. Modern Sciences. Husserl. 


\section{Introdução}

Para Husserl, as ciências europeias atravessam uma grave crise de sentido desde a revolução científica no século XVII. Sustenta ele que o espírito científico moderno se caracteriza por assumir uma nova ideia de objetividade, desejando alcançar a completa exatidão na descrição do mundo natural, e para isso assimila a totalidade do ser a dados matemáticos ou físico-químicos com o fim de obter explicações absolutamente conclusivas. Os resultados técnicos obtidos por tais ciências acabam por legitimar o seu método de pesquisa e as suas concepções. A crise, na concepção husserliana, começa com essa atitude, ela tem um caráter existencial, o que quer dizer que as ciências, reduzindo o mundo ao conjunto dos fatos para poder medi-lo, quantificá-lo, determiná-lo, perdem de vista a subjetividade e já não se tornam mais capazes de dar um significado para a existência humana.

Segundo Husserl, desde que as ciências naturais adotaram, nas origens da modernidade, este novo modelo de cientificidade: o de ciência objetiva-experimental, elas abandonaram o sentido filosófico-teleológico que havia na antiguidade, embutido no pensamento grego. Para Husserl, a filosofia constitui uma cultura da razão, e a Europa, eminentemente filosófica desde suas origens, representa o movimento cultural que desenvolve, teleologicamente, a ideia infinita de razão até sua realização última - a de uma humanidade universal e autêntica. A crise, por conseguinte, é um desvio, um desencaminhamento em relação a este itinerário racional tomado pela filosofia. Trata-se, portanto, de um transvio na própria teleologia condutora da razão filosófica. As ciências matemáticas da natureza, que surgem com Galileu, são as representantes máximas desse desvio, dessa deturpação de sentido da filosofia, na medida em que elas se convertem em naturalismo, empirismo, positivismo, e tendem a reduzir todo ser, natureza e subjetividade, à noção pobre e restrita de objeto.

Não se trata, porém, de um problema meramente teórico. Quando Husserl fala de uma crise existencial, ele deixa subentendido que a crise não tem repercussão apenas no âmbito intelectual das ciências, mas que afeta de maneira contundente a cultura e a humanidade europeia como um todo. O problema, então, para Husserl, é a possibilidade de uma ciência filosófica que não seja redutora e empobrecedora do sentido do mundo. Ele está atrás assim de uma filosofia fenomenológica que possa restabelecer as conexões perdidas entre a racionalidade e o mundo da vida. As ciências tradicionais, baseadas na lógica e no intelectualismo objetivista, não podem satisfazê-lo nesse sentido. Concepções como de mundo da vida (Lebenswelt) ou mundo circundante (Umwelt), introduzidas por Husserl, permitem precisamente repensar a questão da ciência e a possibilidade de superação da crise, na medida em que convidam a repensar o mundo pré-dado, que é irredutível à ciência lógico-objetiva e reivindica um novo tipo de cientificidade. É desta cientificidade, em sentido amplo, que se ocupará o presente trabalho, assim como da possibilidade de uma nova ciência não-reducionista a partir da fenomenologia transcendental inaugurada por Husserl.

\section{I - A fenomenologia transcendental: resumo e esboço esquemático}

A fenomenologia foi fundada por Edmund Husserl, entre os anos finais do século XIX e primeiras décadas do século XX, com a proposta de dar um novo impulso ao pensamento filosófico, tentando então restituí-lo à sua origem e radicalidade últimas. Poucos homens se devotaram tão intensamente à investigação científico-filosófica quanto Husserl. Pesquisador incansável, o filósofo seguiu carreira como professor universitário entre os anos de 1883 até 1928, trabalhando em vários institutos: Universidade de Berlim, de Viena, de Halle, Göttingen e Freiburg-im-Breisgau. Durante o período em que exercia o magistério, ele redigiu as obras pioneiras da fenomenologia, dentre as quais se incluem Filosofia da Aritmética (1891), Investigações Lógicas (1901 e 1902), Ideias (1913), Meditações Cartesianas (1929), etc. Husserl formula em tais escritos o método fenomenológico e assume a tarefa de desenvolvê-lo plenamente, fazendo disso sua meta principal, tarefa sobre a qual ele debruça-se incansável e obsessivamente. Os numerosos escritos do filósofo são reunidos posteriormente sob o nome de Arquivos Husserl. 
A grande novidade dessa obra é a mudança operada no próprio estilo de se fazer filosofia. Husserl desejava, na sua época, tornar a filosofia novamente consciente de sua verdadeira vocação, a saber, a vocação de constituir uma ciência universal. Para ele a filosofia, carente de orientação fenomenológica, vive numa cegueira e numa ingenuidade crônicas, uma vez que ela parte de campos de fenômenos já constituídos, omitindo por inteiro o processo transcendental de sua constituição. "Ela só traz para o seu círculo de pesquisa os polos constituídos do objeto, permanecendo cega perante o ser e a vida completa e concreta que transcendentalmente os constitui" (HUSSERL, 2012, p. 144).

O que move a investigação fenomenológica, portanto, é o interesse de reparar essa omissão, voltando os olhos para a vida transcendental da consciência, ou seja, para os vividos que atuam na doação de sentido e constituição dos objetos da ciência. A fenomenologia deve fazer para isso o retorno transcendental, colocando-se no ponto de vista mais originário e profundo do sujeito e pondo-se a descrever os próprios atos de realização transcendental do conhecimento. Sua tarefa é a mais radical de todas. Ela deve ocupar-se em esclarecer: como os fenômenos adquirem o sentido que possuem, tornando-se objeto para a consciência que os visa?

Para Husserl (1953, p. 132), há uma possibilidade concreta na "ideia cartesiana de uma ciência universal a partir de um fundamento absoluto". Ele comunga, portanto, do ponto de vista de Descartes de que a filosofia deve estabelecer-se como fundamento máximo de todas as ciências. E que, nesse sentido, a fenomenologia, como projeto filosófico, deve constituir a base para essa fundamentação. Sua proposta se justifica pelo fato de que as ciências positivas - mesmo no nível técnico elevado das ciências modernas - são ingênuas no que concerne à explicitação de seus conceitos fundamentais. Elas não são capazes de justificar seu projeto científico, tampouco o sentido último do conhecimento por elas conquistado.

Tais ciências, ao se verem desprovidas de fundamentos filosóficos, padecem de uma total falta de evidência. Mesmo sua crítica epistemológica, quando tentada, peca por ser rudimentar e não obter, em absoluto, esclarecer o sentido da existência de seu objeto e de suas elaborações teóricas. Daí, o porquê de elas recaírem em crises, paradoxos, ininteligibilidade. A necessidade que se impõe, portanto, é a de um recomeço radical ou de uma completa reconstrução, tal como se impunha, antes, a Descartes. Assinala Husserl (1953, p. 2) que, devido ao conjunto desses problemas, essas ciências devem ser "membros de uma ciência universal que não é outra senão a filosofia. Não é senão na unidade sistemática desta aqui que elas podem tornar-se verdadeiramente ciências".

A fenomenologia, assim, fornece a base epistemológica absoluta à qual "as ciências empíricas devem recorrer para encontrar seu fundamento definitivo" (HUSSERL, 1953, p. 133). Seu papel é o de conceituação fundamental de todos os domínios científicos. Assim, à medida que a fenomenologia se ramifica, especializando-se em diferentes regiões ontológicas, sua atribuição, em relação às demais disciplinas, é provê-las dos conceitos fundamentais referentes ao ser. Conceitos, aliás, cuja clareza e cuja distinção não admitem mais dúvida possível. Nessa acepção, ela não aceita realidades nem conceitos dados, previamente, sem fazer a pergunta radical pelo seu sentido:

ela deve atingir por ela mesma os sistemas de conceitos que definem o sentido fundamental de todos os domínios científicos. Esses são os conceitos que traçam de início as linhas de demarcação na ideia formal de um universo de existência possível em geral e, por conseguinte, também na de um mundo possível em geral. Eles devem por isso mesmo ser os conceitos fundamentais verdadeiros de todas as ciências (HUSSERL, 1953, pp. 131-132).

Para se ocupar da tarefa mencionada acima, a fenomenologia parece operar num quadro de referências gerais traçado por Husserl. Vamos apresentar nesta seção de maneira breve e propositadamente esquemática alguns dos principais conceitos husserlianos que desempenham um papel-chave na constituição de sua fenomenologia. Chamaremos esses conceitos de referenciais ontológicos, visto que eles colocam em questão, em última instância, o problema do conhecimento científico do ser. Porém, cabe advertir que tentamos nessa 
apresentação alcançar o máximo de concisão, daí, não estamos imunes de incorrer numa certa facilitação ou assingelamento do tema. Por isso, deixamos claro que nossa proposta aqui é apenas uma hipótese, uma suposição que se mostra necessária para o alcance dos objetivos lançados neste artigo.

A partir da introdução geral à fenomenologia presente em trabalhos como "Ideias I" e "Meditações Cartesianas", parece plausível supor que Husserl, em sua tentativa original de leitura do ser, insere o problema num quadro referencial constituído pelos seguintes conceitos fundamentais:

I. A "intencionalidade", que pressupõe uma correlação essencial entre consciência e mundo: toda consciência é consciência de alguma coisa.

II. A tese da "imanência" e da "transcendência", isto é, a distinção entre o ser imanente, absoluto, e o ser transcendente, relativo. Distinção que equivale às regiões ontológicas supremas: o ser como consciência e o ser como realidade.

III. O método de "redução fenomenológica", constituído por três momentos ou etapas: a epoché, a redução eidética e a redução transcendental. A redução se apresenta como método indispensável ao estudo ontológico, tendo em vista a necessidade de suspensão dos pressupostos relativos à tese geral da atitude natural a fim de que, com o retorno ao ego transcendental como sujeito absoluto, ser possível explicitar os processos de constituição pelos quais o ser adquire um sentido a partir da consciência. Isso evidencia o fato de que a questão do ser é inseparável da questão sobre as operações de doação de sentido ao ser por parte da subjetividade constituinte.

IV. A "estrutura teleológica" dos vividos da consciência, conceito pelo qual Husserl mostra que a constituição se dá nos termos de uma teleologia imanente que comanda os atos de doação de sentido e de formação do conhecimento. Essa teleologia imanente estende-se a todas as dimensões da subjetividade humana, não apenas no âmbito epistemológico, mas volitivo, afetivo, etc. Entretanto, essa teleologia não pertence somente ao âmbito individual; ela manifesta-se no indivíduo, mas está ligada, por essência, a uma finalidade mais eminente que inclui toda a humanidade. Aqui, portanto, entra a teleologia no sentido histórico, a qual será discutida por Husserl na Krisis.

O quadro acima está a indicar que a fenomenologia, como ciência descritiva, deve explicitar o sentido do ser a partir desses quatro referenciais ontológicos. O ser é identificado ao objeto intencional, que aparece como transcendente, perfilando-se diante da consciência, e que é constituído teleologicamente a partir das estruturas imanentes do sujeito. Como o ser, em sua totalidade, possui diferentes modos de aparecer, de se fenomenalizar diante da consciência, a ontologia em Husserl é determinada por uma divisão do estudo em regiões ontológicas formais e materiais.

\section{II - A fenomenologia transcendental e a crise das ciências}

Tendo exposto o quadro acima, vamos refletir sobre o nascimento, a história e o desenvolvimento das ciências modernas do ponto de vista da fenomenologia transcendental. Husserl, na sua interpretação histórica, tenta identificar os motivos históricos e filosóficos que levaram a humanidade europeia a entrar numa crise epistemológica e existencial, fazendo-a abandonar gradualmente, de acordo com Koyré (2006, p. 6), "todas as considerações baseadas em conceitos de valor, como perfeição, harmonia, significado e objetivo", e efetuando assim, do ponto de vista científico, uma "completa desvalorização do ser, o divórcio do mundo do valor e do mundo dos fatos".

Para Husserl, a ideia de ciência que surge na modernidade é o elemento configurador central do pensamento no ocidente, é o elemento que dá a este o seu caráter, a sua marca registrada. Refletir, portanto, sobre a ciência, a origem, o sentido, o valor do conhecimento científico, significa refletir sobre o próprio estilo de 
vida que se estabeleceu no ocidente a partir da revolução científica moderna. Refletir, além disso, sobre uma crise das ciências significa repensar o próprio sentido que a vida do homem moderno e contemporâneo passou a ter a partir dessa revolução.

O texto "A crise das ciências europeias e a fenomenologia transcendental" é a última obra de Husserl - publicada postumamente. O filósofo decide nela, pela primeira vez, trazer para o campo de investigação da fenomenologia preocupações e considerações de ordem histórica e cultural. Esse trabalho, com efeito, distingue-se em relação aos demais textos do filósofo pelo fato de tratar diretamente da questão da história europeia. Mais precisamente, da história das ciências europeias sob o ponto de vista teleológico de seu desenvolvimento e de sua crise na contemporaneidade.

O conceito de crise é usado nesse contexto para designar o fato de que as ciências naturais vieram a perder o seu genuíno caráter científico. Isso acontece gradativamente ao longo da história, mesmo apesar de todo o notável sucesso da técnica científica, dos avanços e progressos tecnológicos. Como salienta Morujão (1994, p. 262), enquanto que a "legitimidade do método e a evidência da problemática tornam a ciência inatacável, o mesmo não acontece quanto à sua função na crise da nossa cultura". Os aspectos dessa crise, portanto, não se referem ao rigor teórico e ao êxito prático dos resultados das ciências, que, com efeito, estão fora de discussão.

Como diz Husserl (1956, p. 80): “A crise de uma ciência não indica senão o fato de que o real caráter científico, o modo, em absoluto, pelo qual as ciências estabelecem sua tarefa e desenvolvem uma metodologia para ela, tornaram-se questionáveis". A interpretação, feita na Krisis, busca evidenciar o motivo dessa crise, atribuindo-a ao advento do positivismo. O positivismo está inclinado a reduzir a ideia de ciência em geral à de simples ciência empírica. Ele empenha-se num tipo de redução naturalista que assimila a ideia de "ciência" a uma acepção particular e restrita, como ciência meramente factual.

A racionalidade, a partir dessa concepção, fica limitada assim ao seu mero potencial de aplicação técnica, sendo considerada e avaliada apenas sob esse critério. Assim, a ideia que o positivista apresenta como ciência, escreve Husserl (1956, p. 82), tem sérias implicações em toda a cultura europeia: ela afeta, justamente,

o que a ciência em geral significou e pode significar para a existência humana. A exclusividade com a qual, na segunda metade do século 19, a completa visão de mundo dos homens modernos deixou-se determinar pelas ciências positivas e cegar pela "prosperidade" que estas produzem, significou um indiferente afastamento das questões que são decisivas para uma genuína humanidade. Ciências de orientação meramente factual produzem homens de orientação meramente factual (HUSSERL, 1956, p. 82).

A tendência que, nesse sentido, se estabelece, é a de uma sobrevalorização da racionalidade técnica (tecnocracia), sobretudo nos anos que se seguem à Primeira Guerra Mundial. O problema da crise, portanto, não pode se dissociar do contexto estrutural em que foi pensado por Husserl. A preocupação dele com relação à história europeia data do período histórico em que a Alemanha encontrava-se sob a dominação do regime Nacional-Socialista. Paul Ricœur (1949, p. 281) assinala, com efeito, que "a situação política da Alemanha nessa época está visivelmente sob o pano de fundo de todo este curso de pensamento: nesse sentido pode-se bem dizer que é o trágico mesmo da história que levou Husserl a pensar historicamente". Tendo-se, aliás, em consideração que o filósofo foi perseguido pelos nazistas por ser judeu.

Husserl, assim, vê-se autorizado a propor que a crise das ciências, na verdade, corresponde a uma crise da cultura e da humanidade europeia como um todo. E que se trata, em última instância, de uma crise da própria razão. Do ponto de vista filosófico adotado na Krisis, a história é uma história da razão humana e, como tal, ela obedece a uma teleologia imanente na qual se acha orientada na direção de um desenvolvimento histórico infinito. Há, na visão de Husserl, uma meta derradeira que orienta os acontecimentos filosóficos e científicos da civilização ocidental, desde os primórdios da filosofia na Grécia antiga, rumo à constituição do telos espiritual do homem que é o estabelecimento de um saber absoluto. A finalidade última que reside em tal movimento teleológico é a plena realização daquilo que constitui a definição mesmo do homem: a razão. 
A qualidade de homem é essencialmente de ser homem em grupos humanos ligados pela descendência e pelas relações sociais; e se o homem é um ser racional (animal rationale), ele não o é senão na medida em que toda sua humanidade é uma humanidade segundo a razão - em que ela é orientada, seja de maneira latente para a razão, seja manifestamente para a enteléquia que, uma vez vinda a si mesma e tornada manifesta por si mesma, conduz doravante conscientemente o devir humano. Filosofia e ciência seriam desde então o movimento histórico pelo qual se revela a razão universal, "inata” à humanidade como tal (HUSSERL, 1996, p. 92).

A razão é uma tarefa infinita que a filosofia deve incumbir-se de realizar. Na medida em que ela unifica todos os conhecimentos, "é compreendida dinamicamente como um 'devir racional'; ela é 'a vinda da razão a ela mesma" (RICOEUR, 1949, p. 296). Assim, quando o homem empenha sua vida na realização da razão - ele responde à vocação que lhe é mais originária. Sua vida individual passa então a confundir-se com a história da humanidade, caminhando junto com ela numa mesma direção. A história é, assim, inteligível a partir da teleologia que lhe é inerente. Ricœur (1949, p. 289) esclarece, a esse propósito, que filosofia da história e teleologia constituem conceitos sinônimos:

a história não se empresta a uma reflexão filosófica a não ser por intermédio de sua teleologia: ela aparece implicada por um tipo original de estrutura racional que, precisamente, exige uma história. Não há reflexão direta sobre a história como fluxo de eventos, mas indireta como advento de um sentido. Assim, ela é uma função da razão, seu modo próprio de realização (RICOEUR, 1949, p. 289).

Husserl, ao assumir o ponto de vista da história da filosofia, vê destinada a esta última a finalidade de alcançar uma totalidade de compreensão a partir de uma perspectiva infinita que só compete a ela tomar, na medida em que se converte numa ciência universal. Quando o filósofo, porém, fala de Europa, ele não está se referindo a um território cindido geográfica e culturalmente do resto da humanidade. Antes, ele se refere ao sentido imanente do desenvolvimento do saber europeu que cria laços entre todos os homens e os une em direção a um objetivo comum e universal. A filosofia, na medida em que representa a aptidão para esse saber, "é a 'enteléquia inata' da Europa, o 'proto-fenômeno' de sua cultura (...) ela é o telos da ciência da totalidade do ser" (RICOEUR, 1949, p. 291).

Para Husserl, assim, não importa o quanto as nações europeias possam estabelecer relações de inimizade. Nenhum conflito entre elas exclui o fato de que, no plano interno, existe uma familiaridade essencial que atravessa a todas, superando as diferenças nacionais, e que permite que elas coexistam, essencialmente, ligadas por um sentimento comum de irmandade, de pertencimento a uma mesma pátria e a um mesmo destino. A crise, portanto, não é senão o sintoma de um desvio fundamental dessa teleologia inata.

Para que a desordem da "crise" hodierna possa ser concebida, o conceito Europa deve ser elaborado enquanto teleologia histórica de finalidades infinitas da razão, deve ser mostrado como o "mundo" europeu nasceu de ideias da razão, ou seja, do espírito da Filosofia. A “crise" pode, então, tornar-se clara como o aparente fracasso do Racionalismo. A razão do falhanço de uma cultura racional reside, porém - como foi dito -, não na essência do próprio Racionalismo, mas unicamente na sua alienação, na sua absorção no "naturalismo" e no “objectivismo" (HUSSERL, 2006, p. 51).

\section{III - Separação entre filosofia e ciência: a "física-matemática" de Galileu}

Nessa interpretação histórica de Husserl, a crise que hoje afeta o Racionalismo tem suas origens no Renascimento. Assiste-se, nesse período, a uma desvalorização do estilo medieval de existência em favore- 
cimento de um novo modelo de humanidade, copiado da Antiguidade greco-romana. O caráter que define o homem da Renascença é a busca por uma razão pura, extraída da filosofia, que seja absolutamente livre dos mitos da tradição para explicar o mundo racionalmente, com base apenas na pesquisa científica. Para Cambi (1999, pp. 197-198), trata-se de uma tendência ideológica e cultural que emerge na modernidade e que opera uma dupla transformação:

primeiro, de laicização, emancipando a mentalidade - sobretudo das classes altas da sociedade - da visão religiosa do mundo e da vida humana e ligando o homem à história e à direção do seu processo (a liberdade, o progresso); segundo, de racionalização, produzindo uma revolução profunda nos saberes que se legitimam e se organizam através de um livre uso da razão, a qual segue apenas seus vínculos internos (sejam eles lógicos ou científicos, isto é, analíticos ou experimentais) (...) Será o iluminismo (...) com sua oposição à metafísica e seu vínculo estreitíssimo com a ciência e o seu iter lógico e experimental (CAMBI, 1999, pp. 197-198).

Na medida, assim, em que surge o conceito positivista de ciência, as questões especificamente metafísicas como "razão absoluta", "teleologia", o problema relativo ao "sentido do mundo", caem em descrédito, são menosprezados e relegados ao esquecimento como não compatíveis com a nova ideia de racionalidade.

O homem, levando essa tendência ao limite, perde afinal a fé na filosofia como capaz de conduzi-lo à realização do saber absoluto. O ideal de um método filosófico universal, suposto de fundamentar todas as ciências, logo desabou. Acreditou-se, então, que o único método que poderia alcançar tal êxito, de maneira indubitável, seria o das ciências positivistas. Essas ciências, em breve, passaram a se especializar cada vez mais nas suas áreas, adquirindo cada vez mais o caráter técnico-racional em detrimento daquele caráter propriamente filosófico. "Assim, a filosofia transforma-se em problema para si mesma e assiste-se a um crescimento prodigioso das ciências positivas, cultivadas por especialistas cada vez mais alheios aos problemas filosóficos" (MORUJÃO, 1994, p. 262).

Como nasceu esse ideal de racionalidade positiva e como ele veio a se estabelecer? Um passo decisivo, nesse sentido, foi dado por Galileu, no seu projeto de matematização da natureza. A meta científica de Galileu incluía interpretar a natureza em termos puramente matemáticos, relegando as qualidades sensíveis do mundo à condição de mera aparência. Ele inverte assim a concepção da metafísica de Aristóteles de que a verdade é dada pela experiência dos sentidos. Como descreve Gusdorf:

As matemáticas são a verdade do real: tal é a fórmula da revolução galileana. A verdade, segundo a doutrina de Aristóteles, se revelava ao homem na percepção sensível. Ora, a evidência dos sentidos desmente o rigor matemático; ela é permeável a todas as potências enganosas, às imaginações individuais ou coletivas. A estas ilusões e fantasmas se opõe doravante a luz fria da razão, que dissipa as miragens para reencontrar a ordem universal e inteligível sob a confusão. A verdade não será mais a doação originária do mundo ao pensamento; o pensamento toma o mundo à distância para o decifrar, numa segunda leitura, ao preço de uma forma de desnaturalização. É preciso distinguir, entre os caracteres aparentes dos objetos, aqueles que pertencem à essência inteligível, e aqueles que não tem senão uma significação acidental e derivada. A operação do conhecimento aparece como uma geometria em ação, que distingue entre as qualidades primeiras e inteligíveis do objeto, e as qualidades segundas, que saem da constituição de nossa sensibilidade (GUSDORF, 1967, p. 120).

O projeto de objetivação do mundo encontra nessa ocasião sua culminância histórica. Para Husserl, Galileu é um gênio descobridor e encobridor ao mesmo tempo, pois na mesma proporção em que ele descobre um cosmos ordenado por leis gerais, ele encobre a natureza concebendo-a como uma matemática encarnada. Assim, a consolidação da física matemática - que vai de Bacon a Galileu, de Descartes a Newton 
- é o projeto de uma extrema racionalização do saber. Passa-se, então, a compreender a natureza como pura extensão suscetível de ser explicada, exaustivamente, pela geometria. Wolff salienta que a natureza, concebida nesses termos,

não é senão corpo (...) está, aliás, sempre ao mesmo tempo "fora de si mesma", por assim dizer, no sentido de que todas as suas partes são exteriores umas às outras, partes extra partes - é o que chamamos espaço, ou antes, “extensão". Há uma única matéria, idêntica em toda parte e perfeitamente homogênea. O conhecimento dela pode ser claro e distinto, com a condição de reduzi-la às leis universais da transmissão e da conservação do movimento, que podem ser exprimidas matematicamente como relações entre grandezas (WOLFF, 2012, pp. 52-53).

Outra importante consequência da objetivação matemática da natureza é que ela implica, de modo radical, a substituição da ideia de teleologia ou causa final, de Aristóteles, pela compreensão do movimento natural apenas no sentido de deslocamento. Assim, para Galileu, a natureza pode ser inteiramente geometrizada pela física, ela pode ser descrita matematicamente nos seus pormenores, uma vez submetida aos cálculos do cientista. Por conseguinte, "nada mais há na natureza do que esses corpos sem mistério, não há almas hierarquizadas, nada de qualidades ocultas, nada de finalidade, nada de obscuro ou confuso, isto é, nada que não seja racionalmente pensável" (WOLFF, 2012, p. 53). O mundo inteiro, incluindo os seres vivos, é concebido então "como uma imensa máquina regulada por mecanismos" (WOLFF, 2012, p. 53).

De acordo com Cambi (1999, pp. 209-210), “a matemática é indicada como a regula ad directionem ingenii e as ciências devem encontrar espaço na escola, não mais como ciências dedutivas e filosóficas (à maneira aristotélica), mas como ciências empíricas e experimentais", logo, isso vem impor a toda à ciência "um modelo de racionalidade que determina comportamentos intelectuais diferentes daqueles que predominavam no humanismo clássico".

Leibniz, mais tarde, assumindo essa tendência de pensamento, sonha em resolver todos os problemas de fato (matters of fact) em termos puramente lógicos. Laplace, por sua vez, projeta reduzir toda natureza a um conjunto de relações mensuráveis, determináveis e previsíveis segundo fórmulas matemáticas exatas. A natureza inteira seria uma espécie de laboratório para o físico. Laplace conjetura até mesmo sobre a possibilidade de um vasto intelecto, chamado por ele de intelecto-demônio, que, onisciente, seria capaz de conhecer, em dado momento, o conjunto de todas as forças mecânicas que atuam no universo, que conheceria a totalidade do tempo, podendo prever e controlar o futuro.

Para Husserl, a obsessão da ciência moderna por tal modelo de objetividade obriga-a a assumir um ponto de vista reducionista e empobrecedor do significado pleno do mundo. A subjetividade humana perde também a capacidade de compreender a si mesma, na medida em que tende a aplicar ao mundo em geral apenas as categorias regionais da física-matemática, e interpreta, desse modo, o conjunto do ser apenas sob o modelo da matéria. De fato, essa ontologia é adotada, como teoria de fundo, em todas as ciências naturais, refletindo-se inclusive no psicologismo, com os empiristas ingleses, os quais buscam estudar o pensamento a partir da noção de causalidade psíquica copiada da categoria de causalidade material. "A distância entre o sensível e o inteligível deixa de se manter. A natureza é unificada e uniformizada e considerada um universo matemático" (MORUJÃO, 1994, p. 265).

De acordo com Koyré, a revolução científica e filosófica da modernidade

causou a destruição do Cosmos, ou seja, o desaparecimento dos conceitos válidos, filosófica e cientificamente, da concepção do mundo como um todo finito, fechado e ordenado hierarquicamente (...) e a sua substituição por um universo indefinido e até mesmo infinito que é mantido coeso pela identidade de seus componentes e leis fundamentais, e no qual todos esses componentes são colocados no mesmo nível de ser (KOYRÉ, 2006, p. 6). 
Quando Koyré se refere a esse nivelamento ontológico, ele remete ao fato de que a física-matemática reduz a totalidade do mundo à pura extensão, ou seja, apresenta a natureza como um espaço homogêneo passível de ser determinado e submetido aos cálculos e medições do geômetra. Essa concepção diz que há, por trás dos fenômenos, um substrato de verdades em si, de ordem lógico-matemática, e que todo o resto, as coisas sensíveis, visuais, táteis, sonoras, gustativas, não passam de um revestimento ilusório que encobre o ser verdadeiro, elas não têm, portanto, valor algum de objetividade. Logo, devem ser abstraídas de toda consideração teórico-científica.

No entanto, a fenomenologia inaugurada por Husserl levanta várias e sérias objeções contra este modelo de objetividade adotado pelas ciências naturais.

\section{IV - Crítica à física-matemática}

Husserl deve primeiro desembaraçar-se da concepção, aceita entre os homens de ciência, segundo a qual há uma distinção entre qualidades "primárias" e "secundárias". Essa concepção, pois, estabelece que o conhecimento real só se efetua sobre as qualidades físico-matemáticas do objeto, e não sobre as qualidades sensíveis. Com isso está pressuposto que as qualidades físicas são a estrutura primeira e originária do ser, quer dizer, "as qualidades sensíveis espécificas devem ser 'puramente subjetivas' e apenas as qualidades físico-geométricas 'objetivas' (Objectiv)” (HUSSERL, 1950, p. 128). O resultado disso é crer que as propriedades olfativas, gustativas, táteis, a visão, a audição, constituem uma simples aparência da coisa sem valor algum de objetividade. Essa tese conclui, assim, que, ao despir o invólucro sensível de algo, ficamos com a coisa tal como ela é verdadeiramente. Ou seja: somente com seu esqueleto lógico.

As qualidades sensíveis são "simples resultado" da interação entre consciência e mundo, não são propriedades que a coisa contém em si mesma. Elas não passam, portanto, de um revestimento que esconde o aspecto real do ser. O modelo da física, abstraindo o sensível, apresenta a matéria em termos de átomos, íons, aceleração, força, energia, etc. A determinação dela passa a ser de ordem geométrico-matemática. Quer dizer: uma ordem imutável e absoluta, ao passo que a experiência é relegada ao domínio do contingente, do incerto. Podemos separar, portanto, todas as qualidades sensíveis do objeto que não passam de signos, que não seriam "reais" no sentido pleno da palavra. É nesse paradigma que culmina o projeto científico de objetivação do mundo natural.

Husserl consente em que, de fato, a experiência singular não oferece matéria para uma asserção objetivamente justificável de valor universal. Como o objeto, na experiência, se mostra apenas parcialmente, por lados, por aparições, o ser experienciado só é determinável por recurso a uma ideia que reside no infinito. $\mathrm{O}$ modelo de verdade construído acerca desse ser é regulado de acordo com tal ideia, a qual não é propriamente uma ideia exata, fixa, pois, como diz Husserl, posto "que cada experiência pode a priori conter elementos de discordância, que são eliminados na experiência mais ampla e na sua síntese, a determinação da ideia a alcançar a partir da experiência pode não só ser unilateral mas também em parte falsa” (HUSSERL, 2012, p. 224).

Cada ideia assim não passa de um esboço provisório. Quer dizer, não se fornece de imediato uma ideia última, definitiva, mas tão-só "um primeiro traço, uma exposição, de certo modo, da ideia que reside no infinito e é inalcançável, da qual só a forma é dada, como norma absoluta para toda a construção desses primeiros traços" (HUSSERL, 2012, p. 224). O método científico natural consiste em buscar ponderações dessa ideia pura, a fim de submeter a ela então todos os dados da experiência. "Isto acontece pelo método de tornar exatos os continua, da transformação das causalidades sensíveis em causalidades matemáticas, etc. Só então se pode tomar em atenção o psicofisicamente anômalo" (HUSSERL, 2012, p. 225).

As anomalias da percepção são, desse modo, suprimidas sob a reputação de ilusões, de aparências. Logo, a experiência é considerada um signo, ela é simplesmente subjetiva e indica um substrato objetivo por detrás dela. 


\begin{abstract}
A coisa propriamente experimentada fornece o puro “isto", isto é, um $\mathrm{X}$ por ele-mesmo vazio, que torna-se o portador tanto de determinações matemáticas quanto de fórmulas matemáticas correspondentes; e este $\mathrm{X}$ não existe no espaço da percepção, mas em um "espaço objetivo" do qual o primeiro é simplesmente o "signo", a saber, uma multiplicidade euclidiana tridimensional de que não se pode ter senão uma representação puramente simbólica (HUSSERL, 1950, p. 129).
\end{abstract}

Husserl não pode concordar com a posição do "X suporte" cuja consequência é reduzir a coisa física à condição de "pura aparência' (...) um simulacro ou uma imagem-retrato (Bild) errônea da 'verdadeira coisa' física” (HUSSERL, 1950, pp. 170-171). A tendência da ciência natural, porém, é eleger as qualidades primárias para a posição de "causa desconhecida" do mundo sensível. Sua hipótese consiste em que a realidade secundária é o efeito de "uma realidade totalmente desconhecida que seria em relação a tais aparências uma causa escondida que se poderia somente caracterizar de forma indireta e analógica pelo viés de conceitos matemáticos" (HUSSERL, 1950, p. 171).

O argumento, porém, é inválido, pois, na medida em que a "coisa" só pode ser dada de forma sensível, submetida ao modo de aparecer sensível, por princípio, essa causa desconhecida deveria ser percebida também numa experiência possível, "se não para nós, pelo menos para outros eus dotados de uma visão melhor e mais ampla” (HUSSERL, 1950, p. 172). Além disso, é necessário que a percepção, ao surpreender a causa desconhecida, venha fazê-lo também por intermédio das "aparências"; assim, por princípio, seríamos obrigados a perguntar por uma nova causa desconhecida de tais aparências, enredando-nos numa regressão ao infinito.

Husserl recusa admitir, em absoluto, que as determinações sensíveis são um simples sinal da estrutura matemática, que elas revestem tal estrutura dissimulando-a do olhar da experiência. Para ele, a coisa física não serve de sinal para outra coisa. "Ao contrário, a coisa física não é estranha a isto que aparece corporalmente aos sentidos; ela se anuncia nessa aparência, e mesmo a priori (por razões eidéticas irrecusáveis) não se anuncia de forma originária senão nela" (HUSSERL, 1950, p. 173). Ela não serve, pois, senão de sinal para si mesma.

O filósofo rejeita como absurda a tentativa de estabelecer relações de dependência causal entre o primário e o secundário. A própria ideia de seriação "primeiro-segundo" induz a erro. Com efeito, tendo em conta a intencionalidade dos atos, vemos que os modos de intuição são equivalentes entre si. Da mesma maneira como subsiste uma intuição voltada para as determinações sensíveis do objeto, segue-se, pois, uma voltada para as determinações de ordem matemática. Toda hierarquização aqui em termos de causalidade soa, no mínimo, ilusória: "é somente na medida em que este $\mathrm{X}$ é o sujeito das determinações sensíveis que ele é também o sujeito das determinações físicas, as quais de seu lado se anunciam nas determinações sensíveis" (HUSSERL, 1950, p. 174). Sem contar, além disso, que o pensamento só pode determinar logicamente seu objeto físico na medida em que já está "sobre o alicerce da experiência natural" (HUSSERL, 1950, p. 175). É sobre a experiência, pois, que ele se edifica.

Pelas razões levantadas acima, e a fim de incluir ambos os modos de intuição, Husserl utiliza dois termos, na língua alemã, para se referir a objeto: Objekt e Gegenstand. O primeiro deles - Objekt - é alusivo ao objeto do conhecimento matemático-experimental. Em oposição a ele, Gegenstand, por sua vez, irá corresponder ao objeto da percepção ou da representação empírica. O que importa ainda acrescentar, sobre o motivo de tal diferenciação, é que o primeiro conceito, Objekt, possui uma estrutura "muito rígida para exprimir o conteúdo da vida", isso pelo fato de pressupor o objeto "sempre sobre o mesmo tipo e sobre o mesmo plano" (LÉVINAS 1994, p. 123), sem admitir níveis, variações e modos de existir diferentes. A escolha de Gegenstand ou Gegenständlichkeit (objetidade), portanto, não é casual, ela vem atender à necessidade de exprimir a objetividade de maneira mais maleável, de modo a incluir a multiplicidade dos sentidos de ser, os modos efetivos ou eidéticos de existência, o estado de coisas (Sachverhalt). É desse objeto, em sentido mais vago, que se ocupa a análise fenomenológica. 


\section{V - Conclusão}

A proposta de Husserl, na Krisis, é examinar o modelo de ciência acima sob o ponto de vista de seu estabelecimento histórico, assumindo já, de saída, que ele operou uma profunda ruptura com a teleologia inata que animava a pesquisa filosófica desde a antiguidade. Essa ruptura operada pela Revolução Científica, porém, é parte de uma transformação muito mais ampla e radical, já que a modernidade rompe, em certo sentido, com a própria paideia grega, entendida nessa acepção que lhe confere Jaeger (1994, p. 7) de ser uma unidade de sentido, que incluía civilização, cultura, educação, literatura, tradição, arte, a qual, no passado helenístico, movia a "própria história da Grécia na realidade concreta do seu destino vital", ou seja, a "formação de um elevado tipo de Homem”.

Para Husserl, o naturalismo (o conjunto das ciências naturais ou empíricas) comete dois erros de princípio: ele negligencia a subjetividade constituinte e confunde ciência em geral com ciência lógica-objetiva. Com relação ao primeiro erro, é apontado que a ciência, na sua obsessão pela objetividade, esquece que todo objeto está referido, por essência, a um sujeito, ou melhor, é a subjetividade constituinte que dá ao objeto o seu sentido de objeto. Há uma função fundamental desempenhada pela consciência: é ela que constitui todo conhecimento. Não há como abolir a subjetividade das ciências, uma vez que todo valor de objetividade dado ao mundo tem sua origem na própria subjetividade. Como Husserl adverte:

Só um radical questionar retrospectivo pela subjetividade (...) em última instância geradora de toda a validade do mundo com o seu conteúdo, em todos os seus modos, científicos e pré-científicos, bem como pelo que e o como das realizações da razão - só um tal questionar pode tornar a verdade objetiva e alcançar o sentido último do ser do mundo. Ou seja, o primeiro em si não é o ser do mundo na sua obviedade inquestionada, e não se deve levantar a questão meramente sobre aquilo que objetivamente lhe pertence; o primeiro em si é, ao contrário, a subjetividade e, na verdade, a subjetividade como ingenuamente pré-doadora do ser do mundo e, depois, como aquela que racionaliza ou, o que é o mesmo: que objetiva (HUSSERL, 2012, p. 55).

O segundo erro, por sua vez, é acreditar que a ciência objetiva esgota todas as possibilidades de ciência. Husserl assinala que o mundo da vida (Lebenswelt) é anterior a todas as formulações teóricas e, por isso mesmo, ele é irredutível às categorias tradicionais da ciência. Este mundo, no entanto, possui uma evidência originária a partir da qual se fundam todos os tipos de intelecção científica: matemática, lógica, natural, positiva, etc. "Uma teoria objetiva no seu sentido lógico (...) radica no mundo da vida, funda-se neste, nas evidências originárias que dele fazem parte" (HUSSERL, 2012, p. 105). O que Galileu havia pensado como qualidades primárias, as qualidades físico-matemáticas, são na verdade fundadas no mundo da experiência sensível, e não o contrário.

Para Husserl, portanto, a tarefa lógico-objetiva é só uma dentre as várias possibilidades de se constituir um conhecimento científico, e que impõe-se a necessidade de uma ciência que seja reservada para o mundo não-teórico. Como ele salienta,

nunca se questiona cientificamente a maneira como o mundo da vida funciona em permanência como plano de fundo, como as suas múltiplas validades pré-lógicas são fundamentadoras para as verdades lógicas, as verdades teóricas. E talvez a cientificidade, que este mundo da vida, como tal e na sua universalidade, exige, seja uma cientificidade específica, justamente não lógico-objetiva, e que, como a cientificidade fundamentadora última, o seu valor não seja o de uma cientificidade menor, mas superior (HUSSERL, 2012, p. 101).

Husserl, porém, observa que o estudo do mundo da vida requer uma fenomenologia transcendental. É preciso fazer o retorno radical ao estudo da consciência pura, tal como o esforço de volta ao ego cogito enpre- 
endido antes por Descartes. O intuito é não perder de vista, em absoluto, que a consciência transcendental é a instância fundadora de todo ser, e que mesmo toda natureza, toda objetividade natural, estão referidas a ela, na medida em que recebem por ela seu sentido. Husserl propõe uma ontologia em que a região da consciência é logo vista como radicalmente diferente da região do mundo. Assim, enquanto que a ontologia que se ocupa do objeto material opera com determinadas categorias, aquela dedicada ao estudo da subjetividade deve trabalhar com categorias apropriadas a esta.

Segundo Husserl, impõe-se, nesse sentido, a necessidade de uma recondução à consciência transcendental. Essa recondução só pode ser efetuada através do método fenomenológico, o qual exige que se comece com uma suspensão de todos os juízos da atitude natural e a ausência de todos os pressupostos, para descrever a consciência do ponto de vista transcendental puro. A recomendação de Husserl é tomar o "ser" do mundo, afinal, apenas na medida em que ele "finca suas raízes na subjetividade transcendental" (HUSSERL, 1973, p. 164). Sua suposição é a de que é possível reaver o sentido teleológico da existência, justamente, a partir do retorno à consciência que é doadora de todo sentido, sabendo-se, pois, que "não há jamais qualquer objeto existente em si que não diga respeito à consciência e ao eu da consciência" (HUSSERL, 1973, p. 164).

\section{Referências bibliográficas}

CAMBI, Franco. História da pedagogia. Tradução de Álvaro Lorencini. São Paulo: Editora Unesp, 1999.

GUSDORF, Georges. Les sciences humaines et la pensée occidentale. III: La révolution galiléenne. Tome I. Paris: Les Éditions Payot, 1967.

HUSSERL, Edmund. A crise das ciências europeias e a fenomenologia transcendental. Tradução de Diogo Falcão Ferrer. Rio de Janeiro: Forense Universitária, 2012.

A crise da Humanidade Europeia e a Filosofia. Tradução e Introdução de Pedro M. S. Alves. Centro de Filosofia / Universitas Olisiponensis,Phainomenon / Clássicos de Fenomenologia, Lisboa, 2006, pp. 119-152. 1973b.t. 1.

Cartesianische Meditationem und pariser vorträge, Husserliana, Den Haag: Martinus Nijhoff, Husserliana,

Die Krisis der europäischen Wissenschaften und die transzendentale Phänomenologie, Husserliana, vol. VI, Haag, M. Nijhoff, 1956.

Ideen zu einer reinen Phänomenologie und phänomenologischen Philosophie, 1. Allgemeine Einführung in die reine Phänomenologie. Jahrbuch Philosophie und phänomenologische Forschung, $1^{\circ}$ vol., Halle, 1913, p. VIIXIII, 1-323.

Idées directrices pour une phénoménologie. Traduit de l’Allemand par Paul Ricoeur. Paris: Éditions Gallimard, 1950.

Méditations Cartésiennes. Traduit par Gabrielle Pfeiffer et Emmanuel Lévinas. Paris: Librairie Philosophique J.Vrin, 1953.

JAEGER, Werner. Paideia: A formação do homem grego. Tradução de Artur M. Parreira. - 3º. ed. - São Paulo: Martins Fontes, 1994.

KOYRÉ, Alexandre. Do mundo fechado ao universo infinito. Tradução de Donaldson M. Garschagen; apresentação e revisão técnica Manoel Barros da Motta. - 4º.ed. - Forense Universitária, 2006.

LÉVINAS, Emmanuel. Théorie de l'Intuition dans la Phénoménologie de Husserl. Paris: Libraire Philosophique J.Vrin, 1994.

MORUJÃO, Alexandre Fradique. Husserl e a Interpretação da História da Filosofia Moderna. Revista Portuguesa de Filosofia. T. 50, Fasc. 1/3, Homenagem ao Prof. Doutor José do Patrocínio Bacelar e Oliveira (Jan. - Sep., 1994), pp. 261-275.

RICEUU, Paul. Husserl et le sens de l'Histoire. Revue de Métaphysique et de Morale. 54e Année, No. 3/4, Les Problèmes de l'Histoire (Juillet-Octobre 1949), pp. 280-316.

WOLLF, Francis. Nossa Humanidade: de Aristóteles às neurociências. Tradução de Roberto Leal Ferreira. São Paulo: Editora Unesp, 2012. 